number of institutions. Control engineering, for example, would be supported principally in Cambridge, Imperial College and the University of Manchester Institute of Science and Technology. There would in addition be a number of second-tier departments in which specialized lines of research could go on, but the SRC could not support any other department on the scale of the top three unless its programme "turned out to be of outstanding brilliance and industrial importance, and unless arrangements for collaboration and sharing of expensive equipment have been made". Meanwhile, he suggested that the favoured centres should remember that they have a special responsibility to less well supported departments.

\section{Sciences in Parliament}

THIs week the scientific section of the House of Commons Library celebrated its second anniversary, and it is more than a little sobering to realize that the section is such a recent innovation. It seems also to be still possible for the needs of some 630 members to be served by a scientific section of two within the larger research section of the library. Dr John Poole is in charge of the scientific section and is assisted by Dr Diana Holden. So far they seem not to be grossly overworked, but it is clear that if the growth of enquiries continues at present rates, the staff will have to be increased. At present, the section deals with about 400 enquiries a year, although there are only a few members-perhaps no more than twenty-who take an intelligent interest in science.

The work of the Select Committee on Science and Technology and the Select Committee on Agriculture has clearly acted as a great stimulus to the library. In this sense, though the staff of the library would be far too polite to say so publicly, the scientific section could help to repair the deficiencies in the machinery of the House of Commons described two weeks ago by the clerk of the house, Sir Barnett Cocks. Sir Barnett criticized the Treasury sharply for not allowing the house to increase the number of clerks from thirty-six to forty-six. The clerks are now very seriously overworked, and new ones are hard to recruit. The library staff naturally occupies a rather different position from the clerks, but its members have been sitting in on sessions of the select committees, analysing documents and providing information. Library staff try to adopt an unbiased position, and leave the political interpretation of the information they provide to the whim of the individual member. Thus they provide all information short of actual advice - a position they apparently find neither difficult nor frustrating. Actually, there is probably less scope for work of this sort during the present select committee investigation into defence research, as there is far less documentation available for analysis. The sub-committee investigating coastal pollution, on the other hand, is overburdened with documentation and would be wise to take full advantage of help from the library staff. Without it, there is a distinct danger that all the literature gathered together simply languishes in boxes.

\section{Veterinarian Vaccinators}

The British Veterinary Association, which only four months ago maintained that vaccination against foot and mouth disease was a policy of despair, has in the aftermath of the 1967 epidemic changed its mind. It has now become convinced that vaccination is the only way to prevent epidemics of the disease. In its evidence to the Northumberland Committee, the association says that "if, for political reasons, carcase meat is still to be imported from infected countries, the only way to ensure that epidemics do not occur is to supplement the present measures with a well organised programme of systematic vaccination". The association considers that imported infected meat is the major source of infection, and it believes that the risk of airborne infection is steadily diminishing because of better control of the disease on the continent. Increased international trade and travel is tending to make the world a single ecological unit, but it is impossible to judge how serious this risk is, although it is certainly less than that from tainted meat. Only one outbreak of foot and mouth disease, in Canada in 1951, has been traced to a human carrier.

If meat imports from South America are to continue, the association now firmly believes that vaccination should be used as an adjunct, not an alternative, to slaughter. In its evidence, the association discounted the arguments against vaccination in the Gowers report. Modern vaccines give better and longer protection and, as French experience shows, it is possible to prevent epidemics even though calves and sheep are unprotected. Moreover, vaccines which are effective for pigs are expected to be available soon. The association estimates that the cost of vaccinating all cattle and sheep in Britain would be $£ 3$ million a year, which is probably less than the average real cost of the slaughter policy even in good years.

Under the association's scheme, all adult cattle would be vaccinated once a year and calves would be vaccinated twice within a three month interval once they had reached four months. Lowland sheep and pedigree pig herds would also be vaccinated, but hill sheep and other pigs might be left unvaccinated. Keeping unvaccinated pigs on the same farm as large cattle herds would be prohibited. In the event of an outbreak, all stock in the infected area would be given a booster dose of monovalent vaccine against the appropriate sub-type of the virus.

The association believes that several factors contributed to the breakdown of control in the recent epidemic. It claims that methods of livestock production have changed more in the fourteen years since the Gowers report than in any previous century. Larger herds, increased movement of cattle and new farming methods, all help the spread of the disease. The association draws the obvious parallel between foot and mouth disease and Newcastle disease or fowl pest, which, with the increased sophistication of the poultry industry, could not be controlled by slaughter, with the result that vaccination had to be introduced in 1962. The association accepts the meteorological evidence that wind and rain were important factors in the spread of the epidemic (see page 121); it suggests that danger of windborne spread could be minimized if slaughter immediately followed prompt reporting of the disease instead of being delayed, sometimes for two to three days, while the cattle are valued. Why not base this valuation on the corpse of an animal?

The association also proposes that control measures need to be tightened and an advisory board established, 
consisting, among others, of the chief veterinary officer and the directors of the Animal Virus Researeh Institute at Pirbright and the Microbial Research Establishment at Porton. The association also asks that the Ministry of Agriculture veterinary staff be brought up to the levels recommended as long ago as 1954 in the Gowers report. The ministry is understaffed at present, and more than 85 per cent of the 270 qualified staff now employed are over 40 years old.

\section{No Substitute for $300 \mathrm{GeV}$}

NuCLear physicists in Britain may take some crumbs of comfort from the knowledge that the British decision not to support the European $300 \mathrm{GeV}$ accelerator does not extend to the rest of the programme of the European Organization for Nuclear Research (CERN). This includes the development of equipment which in many ways can be considered equivalent to a conventional accelerator of $1,700 \mathrm{GeV}$, and may to some extent at least compensate physicists for the disappointment they are feeling just now.

According to the half-yearly report, work on the intersecting storage rings is coming on well and should be finished on schedule during 1971. What is more, the budget for the project is being adhered to, a factor worth noting as escalation of the cost of CERN projects is one of the criticisms the organization has had to face in the past. As Professor Brian Flowers said at the CERN Council meeting, the intersecting storage rings will give European physicists a unique instrument which will enable some further advances to be made in the physics of very high energies.

It is clear, however, that the intersecting storage rings are only a poor substitute for the $300 \mathrm{GeV}$ accelerator. For one thing, they are far less versatile and can only produce collisions between two beams of protons. Another factor is the difficulty of recognizing the products of the collisions. In a conventional accelerator the secondary particles may have some of the high kinetic energy of the bombarding particles, and come off in more or less the same direction as the primary beam. Detection should be far less easy in the new equipment. Secondary particles will tend to have lower speeds and may be ejected in any direction. Although European nuclear physicists will be pleased to have this machine at their disposal, they are not going to be satisfied with its limited capabilities as a substitute for the $300 \mathrm{GeV}$ accelerator.

\section{More Power for the Ministry}

A REPORT submitted to the Minister of Agriculture in January recommended that the National Institute of Agricultural Botany should be more closely associated with the ministry. In a written reply to a question from Mr Tony Gardner on June 28, Mr Cledwyn Hughes, the Minister of Agriculture, said that the report is now under consideration. On the same day Sir Harold Sanders, chairman of the council of NIAB, informed the annual general meeting of fellows of the institute about the recommendations.

NIAB, set up forty-nine years ago, tests new crop varieties and seeds which are sent from plant breeding stations in Britain and abroad. Recommended lists of varieties are published, in accordance with the institute's aim of improving the yield and quality of farm crops by encouraging the use of better varieties and seeds. The need for changes in the organization of NIAB has been precipitated by the effects of the Plant Varieties and Seeds Act of 1964, which gave plant breeders rights to control by licence the sale and reproduction of their own varieties. The act made provision for an index of varieties to be set up, and for statutory trials to be carried out on varieties submitted either for a grant of rights or for inclusion in the index. Because the systematic botany branch of NIAB undertakes these tests, for which it is ideally qualified, the institute now has members of staff who are responsible to the Controller of Plant Variety Rights.

To remove this dichotomy of responsibility, a joint review group with members from the ministry and from the council of NIAB recommends that the minister, who is responsible to Parliament for the proper functioning of the Act, should have increased representation on a council which would have general direction of all the institute's work. This council would consist of eight members appointed by reason of their posts, including the Controller of Plant Variety Rights and the director of NIAB; five members selected by the Minister of Agriculture-at present he approves the chairman and appoints three other members; eight nominees of various bodies such as the National Farmers Union; five members coopted by the council, and two elected by the fellows. The changes involved would produce a council whose members shared a greater variety of expertise in science and agriculture than before. This council would be able to carry out a wide range of functions in conjunction with the Ministry of Agriculture. Thus the council would have control over the statutory trials which it now carries out on behalf of the Controller of Plant Variety Rights.

To complete the connexion with the ministry, the incorporation of all staff into the Civil Service has been recommended. As yet, it is not possible to see how this recommendation would be affected by changes arising from the Fulton Report on the condition of the British Civil Service.

\section{Repairs at Jodrell Bank}

AFTER more than ten years of nearly continuous operation, Manchester University's Mark I radio telescope at Jodrell Bank is due for an extensive overhaul. The sum of $£ 400,000$ has been allocated by the Science Research Council to cover the cost of repairs and engineering modifications. With the great success in radioastronomy over the past few years, Sir Bernard Lovell has obviously found this new sum far easier to raise than the $£ 663,000$ spent on building the telescope in the 1950s. At that time, he received only half of the total cost from the government-the Department of Scientific and Industrial Research. The Nuffield Foundation contributed a further $£ 205,000$, but the remaining sum was made up of money from a Manchester University appeal, a grant from the United States National Aeronautics and Space Agency and a personal gift of $£ 25,000$ from Lord Nuffield.

There have been no breakdowns since the telescope came into operation in 1957, but in 1967 fatigue cracks appeared in the cones carrying the 800 ton bowl to the trunnions on the tower structures and immediate action is needed. In addition to removing the stresses on the tracks and in the steelwork, engineering modi- 